Original Article

\title{
THE NATURAL AND PREVALENCE OF MEDICATION ERRORS IN A TERTIARY HOSPITAL IN INDONESIA
}

\author{
ANDIKA DWI MAHENDRA ${ }^{1}$ \\ 1Department of Pharmacy, dr Soeradji Tirtonegoro General Hospital Medical Center, Klaten, Indonesia \\ Email: andikadwimahendra@gmail.com
}

Received: 26 Jan 2021, Revised and Accepted: 20 Mar 2021

\begin{abstract}
Objective: Medication error is the most common errors in a hospital setting and a serious issue that intimidate the safety of the patient and may cause mortality and morbidity. The aim of this study is to explore the rate of medication errors reporting in an Indonesian hospital.
\end{abstract}

Methods: This study is retrospective and descriptive. This research was conducted at dr. Soeradji Tirtonegoro General Hospital Medical Center from January to June 2020. Medication error reporting, which was reported for six months, was the sample of the study.

Results: On the period, 105,171 prescribing sheets were collected. 9.5\% of the total prescribing sheets are categorized as Medication Error (ME). The highest incident of ME was prescribing error (88.24\%), then followed by transcribing error (7.61\%), dispensing error (4.02\%), and the last was administration error $(0.13 \%)$.

Conclusion: The most common incident occurred at prescribing stage because the hospital is not supported by electronic prescription. Medication error is an inevitable event during the medication process. But, the incidents can be minimized by implementing some preventive strategies to improve patient safety and safe drug use.

Keywords: Medication error, Medication error incident, Pharmacy service, Prescribing error, Indonesian hospital

(c) 2021 The Authors. Published by Innovare Academic Sciences Pvt Ltd. This is an open access article under the CC BY license (https://creativecommons.org/licenses/by/4.0/) DOI: https://dx.doi.org/10.22159/ijcpr.2021v13i3.42096 Journal homepage: https://innovareacademics.in/journals/index.php/ijcpr

\section{INTRODUCTION}

Current pharmaceutical service is different thirty years ago. Nowadays, pharmaceutical service is concerned with patient care (pharmaceutical care) than drug-oriented. Pharmaceutical Care is responsible and direct of medication-related care for a patient to achieve high quality of care, safe medication, and specific outcome [1,2]. Heppler and Strand coined the definition of pharmaceutical care as a responsible drug therapy provider for achieving the specific outcome and improving quality of life. This process involves collaboration among patients, doctors, nurses, and health care professionals to design, implement, and monitor a planned therapeutic [3]. Medication Errors (MEs) are events which can cause harm to the patient but it is preventable. ME itself began to be a concern in 1999 after the Institute of Medication (IOM) had reported unexpected incidents in hospitalized patients in America, totaling 44,000 incidents [4]. The occurrence of ME is a pivotal indicator to measure the rate of patient safety. ME takes place at four stages, prescribing, transcribing, dispensing, and administration [5].

In the world, error due to ME reaches 51,8\% [6]. In Indonesia, the incident of MEs has not been recorded accurately and systematically. However, the incidents are often encountered in health care services [7]. A study of ME in the hospital revealed that the rate of the events was ranging from 3-6.9\% for in-patient service [8]. The highest error occurred at the prescribing stage with the rate of $74.53 \%$ and $36.91 \%$ at the administrative stage [9]. Another research in government hospitals reported 226 (98.69\%) of 229 prescriptions were detected as an error. The errors consisted of prescribing errors (99.12\%), pharmaceutical errors (3.02\%), and dispensing errors (3.66\%) [10]. The following study was conducted in a teaching hospital, Indonesia. A total of 7,662 drug prescriptions, 1,563 prescriptions were ME (20.4\%) with details of $59 \%$ on administration error, $15 \%$ (transcription error), 14\% (dispensing error), and 7\% (prescribing error). $10.3 \%$ of these errors were classified as potentially significant and $2.4 \%$ as potentially serious [11].

The purpose of the study is to describe medication error incidents, especially in Indonesia. Then, the study was also conducted to enrich online reference of medication error.

\begin{abstract}
MATERIALS AND METHODS
A retrospective descriptive single-centered study was taken place at dr Soeradji Tirtonegoro General Hospital Medical Center. All occurrence reports related to medication errors were collected retrospectively from January to June 2020. The hospital is a top referral hospital in the central java of Indonesia and provides a wide-ranging of clinical services, including emergency medicine, pediatrics, critical care, oncology, surgical, and diverse medical specialties and sub-specialties. Data were analyzed and presented as a percent. This research has obtained approval with a license number DP.02.01/III.1.2/567/2020.
\end{abstract}

\section{RESULTS AND DISCUSSION}

During the six months, there were 105,171 prescription sheets. Forty-five thousand and four hundred and ninety-two (43.26\%) prescription sheets were in-patient prescription. The second highest was out-patient prescription followed by pharmacy service in the emergency department, pharmacy service in the surgical center department, and pharmacy service in chemotherapy and sterile preparation. Of entire of prescription sheets, 9.5\% were medication error that consisted of $88.24 \%$ (prescribing error), $7.61 \%$ (transcribing error), $4.02 \%$ (dispensing error), and $0.13 \%$ (administration error). At prescribing stage, there were 13 identified errors (fig. 3) which the most frequent errors were missing patient's weight, unknown allergies, and no diagnosis.

$\mathrm{ME}$ is any preventable event that might lead to inappropriate use of medication and could harm the patient while the medication is under the control of a healthcare professional. ME caused at least one death and injuries as many as 1.3 million people each year in the United State. Meanwhile, for low to middle-income countries, the incident of MEs are estimated to have the same incident rate as highincome countries. Also, the cost arising from the ME incident reached US $\$ 42$ billion annually or nearly $1 \%$ of total global health expenditure [12]. In this study, ME divided into four stages, prescribing, transcribing, dispensing, and administration. 9.5\% of the total prescription sheets included ME (fig. 1) and more than $80 \%$ 
of ii was prescribing error (fig. 2). At the prescribing stage, there were 13 identified errors. The most common error in prescribing included missing patient's weight, unknown allergies, and no diagnosis (fig. 3). Research carried out in the geriatric ward of the teaching hospital showed that there was a $20.4 \%$ error of 7.662 prescriptions. The percent error was 59\% (administration error), $15 \%$ (transcription error), 14\% (dispensing error), and $7 \%$ (prescribing error) [11]. We found the contrast result of the rate of medication error between our study and in the geriatric ward in a teaching hospital. In our study, the hospital is not supported by electronic prescription that will affect on sequel process of prescription service. Consequently, at prescribing stage, we noticed the higher error and made this stage was the highest incident of medication error. According to this comparison, one of the ways to minimize ME and improve patient safety by the implementation of electronic prescription [13]. The research compared to before and after implementation of electronic prescription resulted significantly to reduce medication error [14].

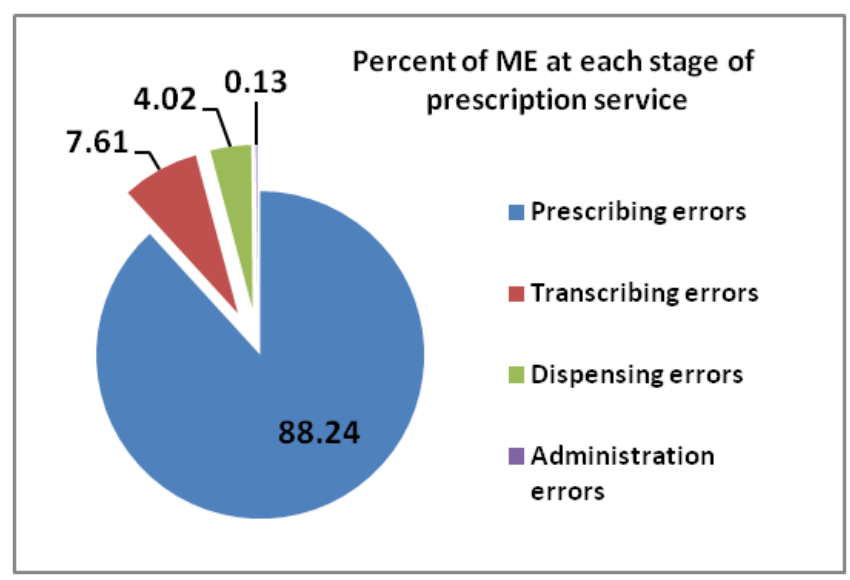

Fig. 1: Medication error incident from January to June 2020

Transcribing process is the next process of prescription service and also the second-highest error occurred. Transcribing is a process to transcribe the medication which is prescribed by a physician to Medication Instruction Sheet (MIS). Then, the MIS is used to procure and prepare the medications from a ward pharmacy or the central in-patient pharmacy [15]. During medication preparation, there were several factors which involved increasing incident of ME. The factors are complex prescriptions, heavy workload, personal neglect, unfamiliarity with medication, and new staff [16]. During the 6 mo, the error at this stage was 7.61\%. Transcribing Error (TE) is an error during the process of copying from a prescription or during the process of inputting a drug to a computer for pricing. Error at this stage included wrong dosage, wrong drug, wrong name of the drug, wrong drug strength, or wrong drug preparation. Research of ME in Southeast Asia covering Brunei, Cambodia, Indonesia, Laos, Malaysia, Myanmar, Philippines, Singapore, Thailand, Timor, and Vietnam revealed there were several MEs that took place during medication preparation. The error included wrong dose, omission error, wrong drug, incorrect administration technique, and wrong dose form [17].

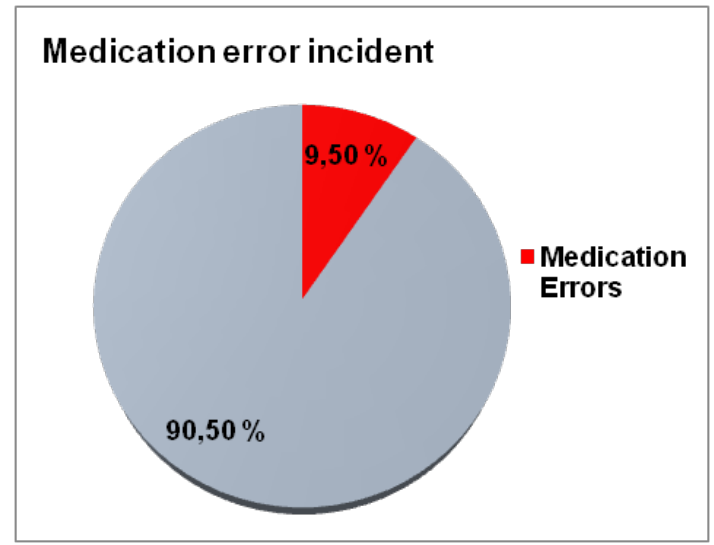

Fig. 2: Percent of medication error in each stage of prescription service in the pharmacy department

Furthermore, the third position was Dispensing Error (DE). The process is started when the drugs start packaging or compounding. Compounding is the process of preparing, assembling, packaging, mixing, and/or labeling a drug or device as the sequel of a physician's prescription drug order. Compounding also can be defined as the action of being made ready drug or device for use in anticipation of a drug order from the prescriber [18]. The number of recognized medication errors during prescription service was an error in taking drug, drug strength, taking the number of drug preparations, and mismatching between the label and the drug in the packaging. After dispensing process, the pharmacist will recheck the suitability among label, drug/device, and instruction of drug use on prescription. If any identified error, the pharmacist directly corrects the errors. Then, the next re-checking will be done on the ward by two nurses before the drug is administered to the patient. A systematic review study revealed that there were involved factors in the dispensing process. The points were work environment (distraction, high workload, low staffing, time of day), product (look- 
alike/sound-alike drug name, likeness product, poor drug labeling), team (communication issue, unskilled staff, loss of concentration due to exhaustion, hurrying through job), and task (ignorance about the task, unreadable handwriting, complex prescription, incautious checking) [19]. Due to the inevitable event, many preventive strategies can be implemented to improve patient safety and lessen the incident. Strategies such as barcode scanning, double-checking, Tall man lettering, for drugs which have similarity in pronunciation, vision, or preparation, can be implemented [20]. Also, to enhance long-term patient safety, analysis of potential factors of ME to formulate preventive steps or conduct RCA (Root Cause Analysis) if the error has occurred.

The next ME is Medication Administration Error (MAE). MAE can occur due to failures in recognizing the five rights (right patient, route, time, medication, and dose) [21]. A focused study on MAE showed that two factors influenced the rate of the incident. Human and the system was the primary factor that contributed causing the event. Human factors were identified as stress, ignorance, fatigue/lack of sleep, poor communication, performance deficit. Among these factors, performance deficit and stress were the top two responsible for MAE. The system, such as frequent distraction, lack of staffing or training, and noise, contributed to an error during the medication process [22]. Our finding, MAE account for $0.13 \%$ of all total MEs. Several errors at this stage included errors in taking infusion or drug, taking drug preparation, and drug strength. The errors took place due to the system and work environment rather than individual performance. Staff shortages, high-workload, and distraction were failures in a system that must be considered to decrease the error. However, it should be remembered that the error can not be separated from the forgetful patient, lack of cooperation, and confusion [17].

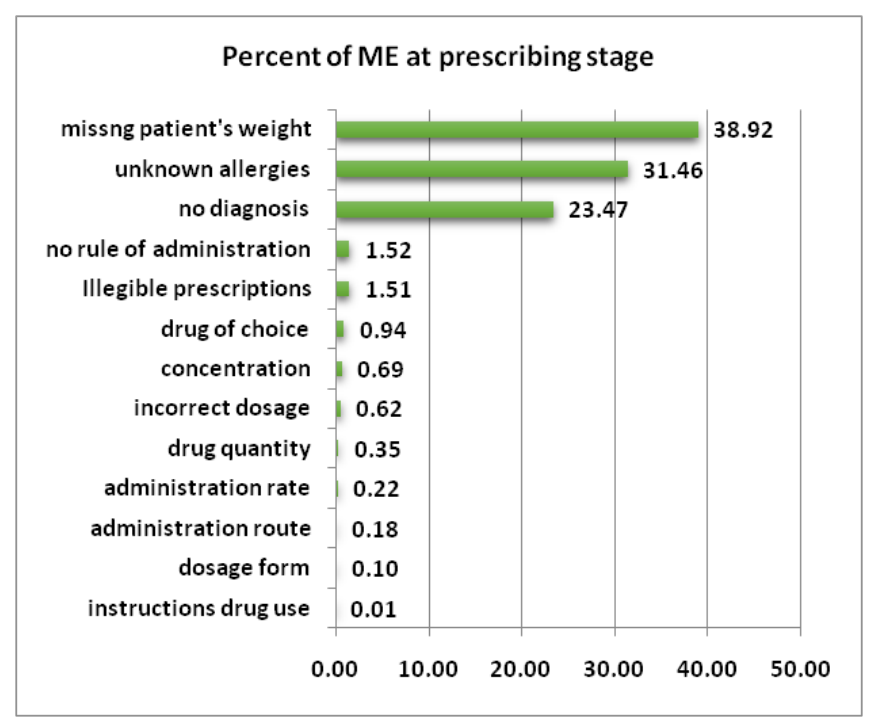

Fig. 3: Percent of medication error at prescribing stage over the six months

Due to difficultness to eliminate the incident of ME, preventive strategies and enhancement of patient safety in medication must be done. Some recommendations which can be applied such as patients/staffs education, double-checking between pharmacist or pharmacist-nurse, the presence of a clinical pharmacist onwards, balancing patient to staff ratios, ensuring adequate and timely supply of the drug onwards, and proper labeling [17]. Research comparing interventions pre and post briefing related to ministerial regulations of health and standards of pharmaceutical services to pharmacists and doctors resulted in a reduction in the ME on prescribing and dispensing. The decrease in prescribing from $16 \%$ to $15.2 \%$ and dispensing $33.3 \%$ to $20.2 \%$ [23].

\section{CONCLUSION}

$9.5 \%$ of 105,171 prescription sheets included medication errors which consisted of prescribing errors, transcribing errors, dispensing errors, and administration errors. The most common incident took place at prescribing stage $(88.24 \%)$ due to the unavailable of health information technology such as electronic prescribing. Medication Errors is an event that can be prevented and it is also difficult to eliminate the occurrence. Preventive strategies are the best way to reduce errors and improve patient's medication safety to achieve the proposed outcome. There are many ways to be chosen to cut off the incidents by improvement in the hospital system and human resources. Patient safety is the priority to guarantee patients receive the best medicine, service, and safety during their medication.

\section{FUNDING}

The study was supported by a research grant from dr Soeradji Tirtonegoro General Hospital Medical Center.

\section{CONFLICTS OF INTERESTS}

The author has declared that no competing interests exist.

\section{AUTHORS CONTRIBUTIONS}

ADM: designed the study, performed the statistical analysis, wrote the first draft of the manuscript, managed the literature searches.

\section{REFERENCES}

1. American Society of Hospital Pharmacists. ASHP Statement on pharmaceutical care. Am J Hosp Pharm 1993;50:1720-3.

2. Sreelalitha N, Vigneshwaran E, Narayana G, Reddy YP, Reddy MR. Review of pharmaceutical care services provided by the pharmacists. Int Res J Pharm 2012;3:78-9.

3. Hepler CD, Strand LM. Opportunities and responsibilities in pharmaceutical care. Am J Health-System Pharm 1990;47:533-43.

4. To Err Is Human: Building a Safer Health System. Washington DC. National Academies Press; 2000. Available from: http://www.nap.edu/catalog/9728. [Last accessed on 04 Feb 2021]

5. Ulfah SS, Mita SR. Review Artikel: medication errors pada tahap prescribing, transcribing, dispensing dan administering. Farmaka 2017;15:8.

6. Fauziyah S, Nur A, Azrifitria A. The impact of pharmacists' interventions to prevent medication errors at a tertiary hospital in central Jakarta, Indonesia. Pharm Biomed Sci J 2019;1:1-6.

7. Dwiprahasto I. Intervensi pelatihan untuk meminimalkan resiko medication error di pusat pelayanan kesehatan primer. Berkala Ilmu Kedokteran 2006;38:1-8.

8. Mutmainah N. Kajian medication error pada kasus stroke di rs x surakarta tahun 2004. J Farmasi Indonesia 2008;4:42-6. 
9. Nurfitria RS, Effendi RNA, Iskandar D. Potential medication errors in electronic prescribing in a primary health care. Indonesian J Pharm Clin Res 2019;02:45-54.

10. Perwitasari DA, Abror J, Wahyuningsih I. Medication errors in outpatients of a government hospital in Yogyakarta Indonesia. Int J Pharm Sci Rev Res 2010;1:8-10.

11. Ernawati DK, Lee YP, Hughes JD. Nature and frequency of medication errors in a geriatric ward: an Indonesian experience. Ther Clin Risk Management 2014;10:413-21.

12. Food and Drug Administration. Working to Reduce Medication Errors. Working to Reduce Medication Errors; 2019. Available from: https://www.fda.gov/drugs/informationconsumers-andpatients-drugs/working-reduce-medication-errors. [Last accessed on 12 Feb 2021]

13. Sergeevna SM, Efimovna LE. Improving training of pharmaceutical specialists for consultation in pharmacy organizations using interactive forms of education. Pharmacophore 2020;11:7-14.

14. Kenawy AS, Kett V. The impact of electronic prescription on reducing medication errors in an Egyptian outpatient clinic. Int J Med Informatics 2019;127:80-7.

15. Shawahna R, Abbas A, Ghanem A. Medication transcription errors in hospitalized patient settings: a consensual study in the Palestinian nursing practice. BMC Health Serv Res 2019;19:644
16. Al-Shara M. Factors contributing to medication errors in jordan: a nursing perspective. Iran J Nurs Midwifery Res 2010;16:1-4.

17. Salmasi S, Khan TM, Hong YH, Ming LC, Wong TW. Medication errors in the Southeast Asian countries: a systematic review. Fuh JL. editor. PLoS One 2015;10:1-19.

18. Allen LV. The art, science, and technology of pharmaceutical compounding. Fifth edition. Washington DC: American Pharmacists Association; 2016. p. 699

19. Aldhwaihi K, Umaru N, Pezzolesi C, Schifano F. A systematic review of the nature of dispensing errors in hospital pharmacies. IPRP 2016;5:1-10.

20. Campmans Z, Van Rhijn A, Dull RM, Santen Reestman J, Taxis K, Borgsteede SD. Preventing dispensing errors by alerting for drug confusions in the pharmacy information system-a survey of users. PLOS One 2018;13:1-11.

21. Agency for Healthcare Research and Quality. Medication administration errors. Patient Safety Network; 2019. Available from: https://psnet.ahrq.gov/primer/medicationadministration-errors. [Last accessed on 09 Feb 2021]

22. Konuru V, Adepu R. A study on medication administration errors in a tertiary care hospital. Indian J Pharm Practice 2011:4:37-42.

23. Azrifitria A, Fauziyah S, Apriliana N. The impact of pharmacists' interventions prevent medication errors at a tertiary hospital in central Jakarta, Indonesia. Pharm Biomed Sci J 2019;1:1-6. 